\title{
LEGITIMAÇÃO SOCIAL EM TEXTOS LITERÁRIOS: STATUS E ETICIDADE NA DRAMATURGIA TRÁGICA OCIDENTAL
}

Sandra Luna

\begin{abstract}
RESUMO: Este artigo revisita a dramaturgia trágica ocidental sob a perspectiva da legitimaçáo social. Analisando períodos distintos dessa tradição teatral, evidencia-se como a relação entre status social e ethos heroico regula o universo dramático, modelando efeitos estéticos, éticos e políticos condizentes com as distintas "estruturas de sentimento" percebidas na história do drama. Da tragédia antiga ao drama moderno, a legitimação social, fundamentando a construção de caracteres, perfaz funçôes inerentes aos gêneros em que se inscrevem os textos.
\end{abstract}

Palavras-chave: Tragédia. Drama moderno. Ethos e status social. Legitimação social. Ação dramática.

\section{Social legitimization in literary texts: status and ethos in western tragic drama}

ABSTRACT: This study reviews the Western tragic drama from the perspective of social legitimization. By analyzing distinct periods of this theatrical tradition, we show how social status and heroic ethos regulate the dramatic universe, modelling aesthetic, ethic and political effects according to different' structures of feeling' perceived in the history of drama. From ancient tragedy to modern drama, social legitimization,

${ }^{1}$ Universidade Federal da Paraíba, Departamento de Letras Estrangeiras Modernas João Pessoa (PB), Brasil. E-mail: lunasand@uol.com.br

DOI: 10.1590/CC0101-32622018183653 
determinant for character construction, accomplishes functions that are inherent to the genres in which texts are inscribed.

Keywords: Tragedy. Modern drama. Ethos and social status. Social legitimization. Dramatic action.

A

problemática da legitimação social habita o centro do universo literário desde as origens da tradição ocidental. Sendo o status social dos personagens determinante à constituiçáo do seu ethos, é possível reconstituir a história da literatura examinando como as formas artísticas, em diferentes tempos e espaços, representam os seres humanos em suas vestimentas sociais para engendrar significações estéticas, éticas e políticas. $\mathrm{O}$ maior ou menor grau de legitimação social das personagens será sempre um poderoso recurso na modelagem das personas que nos comovem, nos seduzem, nos desafiam, náo raramente convocando-nos a rever nossos ideais - de beleza, de bondade, de dignidade, de justiça.

Para entendermos na origem a legitimação social como questáo incontornável no universo ficcional, podemos considerar que os mitos, formas germinais do literário, forjavam-se na representaçâo hiperbólica do humano. A despeito do seu apelo à universalidade, a metaforização mítica dos dramas da vida gravita em torno de figuras potentes, superiores: deuses, semideuses e heróis. Com isso, pode-se dizer que a literatura nasce de um impulso para a idealizaçáo, que não se afasta de um impulso para a elitização. Se pensarmos, com Eliade (1992), que o mito indicia o terror da história, para transcender a finitude humana, para confrontar o sofrimento, a dor e a morte por via da capacidade fabular, para vencer, por via da "pulsão de ficção", como a define Sperber (2009), as fragilidades do corpo e do espírito, é necessário evocar seres especiais, divinizados, heroicos.

Considere-se, no entanto, que, se a linguagem mítica era essencialmente metafórica, fundante de verdades por via da palavra de potência, como propóe Frye (2004), a linguagem literária resulta da cooptação do mito pelo logos. Embora mantendo em alto grau a capacidade de metaforizar, a linguagem literária será, por definição, metonímica, carente de fundamento, não se bastará a si mesma, estará sempre fadada a dizer 
isto por aquilo. A literatura é filha da queda do mito. Por ser mimética, representacional, a literatura se torna indissociável da historicidade, à qual recorre para forjar sua aura de verossimilhança, de maneira que, por mais autônomo que possa parecer frente à realidade, o universo ficcional não escapa ao mundo da vida para fazer sentido. Assim, tão logo nasce a mimeses literária, os seres especiais dos mitos assumem as vestimentas de heróis representativos das elites sociais.

Aristóteles cedo observou a categorização e a valoração estética da poesia em relação à condição social dos protagonistas dos gêneros então existentes. Para Aristóteles (1966), embora todas as formas poéticas representem seres humanos em ação, a tragédia e a epopeia ocupam-se de seres "superiores", enquanto a comédia representa seres "inferiores". Essa classificação diz respeito às funçóes inerentes aos próprios gêneros e, para que seja compreendida, deve-se considerar que o heroísmo e a elevaçáo social para os gregos associam-se a uma linhagem divinizada e essa origem privilegiada fazia-se condição primordial para a veiculação das mensagens épica e trágica.

Do ponto de vista épico, a areté, a disposição para a excelência, para a dignidade, legitimava o heroísmo e consagrava a possibilidade de redenção do humano, por exemplo, pela coragem (Aquiles) ou pela astúcia (Odisseu). Do ponto de vista trágico, a mesma areté servia a outra causa: amplificava o terror e a universalidade da morte, pois o elevado status do herói abatido intensificava o sentido de finitude humana, evidenciando que nem mesmo os mais bem-nascidos e dignos escapavam ao horror da tragédia.

Compreende-se, então, que o status social não se constitui como elemento épico ou dramático por uma convenção arbitrária, destituída de significação ético-política, na epopeia, ou filosófico-religiosa, no caso da tragédia. Interessante é pensar que, se para ser herói épico era preciso ser socialmente elevado, valoroso; para ser herói trágico, embora fosse preciso ser elevado, valoroso, de nada valia essa elevação, de maneira que, postos os dois gêneros em comparação, um aclama a heroicidade com todo o elitismo do aparato social que a acompanha, enquanto o outro desmonta a grandeza heroica por meio da tragicidade e a equipara, por via da morte, a qualquer vida humana.

Note-se que, já no contexto grego, embora as convençóes literárias tenham permanecido inalteradas quanto à elevação social dos 
protagonistas da epopeia e da tragédia, os personagens ditos "baixos", sendo convocados às tramas apenas para exercer funçóes socialmente inferiores, por exemplo, de servos ou mensageiros, sempre escapam excessos ou carências de realidade das formas estéticas, ainda que à revelia dos artistas. Ironicamente, a necessidade de dignificar os heróis faz espraiar dignidade no todo ficcional dessas artes ditas elevadas, de maneira que não são poucas as vezes em que "funçóes" essenciais às tramas acabam nas mãos de personagens "baixos", o que rasura, em alguma medida, as linhas divisórias que separam socialmente os homens. Na Odisseia, por exemplo, o fato de Ulisses depender do silêncio do porqueiro e da ama no momento crucial de sua jornada faz-se muito significativo. Se os servos não podem, por questóes de verossimilhança ou de convenção literária, protagonizar açôes heroicas ou demonstrar grandiosidade por meio de eloquentes discursos, Odisseu, o mestre das palavras, será obrigado a reconhecer no valor do silêncio a dignidade desses seres socialmente invisíveis.

Sendo a tragédia o gênero que perpetua as figuras míticas cantadas na épica, no próprio século $\mathrm{V}$ a.C. se daria no teatro grego a fratura entre a elevação social dos heróis e a excelência do seu ethos. Não raro, nas tramas das tragédias, personagens "baixos" se comportam de forma mais digna do que os reis a quem servem. $\mathrm{O}$ vigia do palácio dos Atridas parecerá mais fiel que a rainha Clitemnestra; as servas de Medeia terão mais lucidez que sua senhora e mais dignidade que Jasão. Em Eurípedes, essa dissensão entre status aristocrático e virtude ética já está explicitamente posta. Na Electra, por exemplo, Eurípedes concede mais dignidade a um campônio do que ao rei, e patenteia isso nas açóes e nos diálogos dos personagens. Obrigada a casar-se com um camponês, Electra será poupada pelo marido da consumaçáo do casamento, gesto que poderia ser lido como reforço à ideologia vigente, segundo a qual um servo não ousaria transpor barreiras sociais. Contudo, há, na estruturação de qualquer tragédia, um elemento fabular altamente subversivo que não pode ser esquecido: a empatia. Ao projetar empatia sobre o personagem "baixo" e sonegá-la na caracterização do rei, o dramaturgo nos instiga a perceber a valoraçáo lançada sobre os andrajos do camponês, e não por via da compaixão. Ironicamente, na tragédia, o patetismo estético recairá sobre os grandes.

Por força de uma civilização que, por razões históricas, tenderá a mais realçar a queda do herói trágico do que a dignidade do seu ethos, 
uma vez encerrada a era de ouro das tragédias gregas, a altivez heroica se apartará da figuraçáo ética da dignidade. Nas tradiçóes que perpetuarão a tragédia nos teatros do ocidente, para o papel de herói será ainda necessário, por muitos séculos, ser socialmente nobre, mas essa nobreza não mais se confunde com nobreza de caráter.

O teatro de Sêneca (século I d.C.) seria um marco do afastamento entre status social elevado e dignidade do ethos heroico. Significativa para a concepçáo latina de tragédia, a definição legada pelo renomado discípulo de Aristóteles, Teofrasto, para quem a tragédia é "a catástrofe na vida de um herói” (KELLY, 1993, p. 11), engendrou uma noção simplificada de tragicidade, compatível com o interesse histórico cada vez maior na representação da individualidade e da responsabilidade humana. As intervençóes do destino, patenteadas no teatro grego, acabaram suplantadas por uma noção de tragicidade que realça os erros humanos. Captando essas influências e movido pelo estoicismo, Sêneca compreenderia a tragédia como consequência de erros e excessos passionais, tramando personagens maléficos, convulsivos, no dizer de Auerbach (1994, p. 49), seres “desumanamente sobrehumanos". É assim que a maldade adentra o universo da tragédia, pelo portal elevado da caracterização heroica. Agora, ser grande é também ser grande no mal.

Daqui podemos saltar para a modernidade, considerando a influência de Sêneca e de seus heróis para o teatro renascentista, assim como o legado cristáo dos conceitos de pecado e culpa, tudo isso aliado à noção de sujeito que emerge com o Renascimento. Nos palcos da modernidade, os tratados de Maquiavel, cujos preceitos sobre poder e política são aproveitados em seus dramas e vazados para outros autores, ensejariam os novos heróis-vilóes, verdadeiros crápulas, para quem a pertença à aristocracia se faz mais como possibilidade de vício que de virtude, justamente pelo papel que o poder aí desempenha.

Shakespeare seria primoroso na representação dessa ruptura entre elevação social e virtude ética ou moral. Parte significativa dos seus reis ou nobres são vilóes treinados na retórica do poder do engodo. Interessante é notar a força das convenções, pois mesmo acolhendo a vertente de tragicidade que dissocia nobreza social e virtude de caráter, do ponto de vista linguístico, Shakespeare adota as convençóes que associam a tragédia, palco de heróis, à linguagem poética e elevada, e a comédia, 
gênero de seres "inferiores", à linguagem prosaica. Nas cenas em que personagens "baixos" se inserem nas tramas, Shakespeare (1975) recorre à linguagem cômica. Exemplo disso é a cena dos coveiros em Hamlet (Ato V, Cena I), quando a linguagem se torna prosaica e jocosa, discurso possível aos excluídos. A noção de decoro, formulada por Horácio (1990) em sua Arte Poética (séc. I a.C), havia sido basilar à perpetuação dessas convençóes estéticas plasmadas na associação entre elevação social e sofisticação discursiva, já que um rei não falaria como um plebeu, assim como um plebeu não usaria a elevada retórica da majestade.

É justamente em reação aos artificialismos dessas e de outras convençóes formais, ainda prevalecentes no teatro do século XVIII, que os Românticos travariam seu combate, enunciando no teatro o clamor revolucionário que, nas ruas, faria guilhotinar os reis e empoderar a burguesia. Destituindo os reis e os nobres dos papéis de protagonistas da tragédia, o Romantismo acolheu, para essas funçóes, pessoas comuns, passando a exibir nos palcos os dramas da vida burguesa. Com esse "rebaixamento" no status dos protagonistas, a própria estética da tragédia se "rebaixa": em lugar da retórica elevada, a linguagem prosaica; ao invés dos conflitos de Estado, dificuldades da vida comum, intrigas domésticas, embates com instituiçóes sociais, carências financeiras. Até mesmo a morte se aquieta no palco: em lugar das cenas violentas e convulsivas das tragédias, o drama social figura mortes simbólicas: doença, loucura, falência material e moral.

Esse "drama social”, ponto radical de transformação no teatro, seria, no entanto, submetido a embates críticos centrados justamente nas relações entre convenções estéticas e legitimação social. No século XX, Steiner (2006) considera o nascimento desse drama burguês como a morte da tragédia. Em sua argumentação, a elevação do status dos protagonistas tornava a queda mais profundamente trágica (maior a altura, maior a queda); além disso, como a queda do rei causava a queda do reino, amplificavam-se os efeitos da tragédia. Vale lembrar que, já no século XVIII, dramaturgos e críticos, como Lessing e Diderot, argumentavam que a tragicidade não dependia da elevação social dos protagonistas, nem a estética do drama dependia da retórica elevada para fazer-se arte. Para Lessing (1962, p. 38-39), quando nos comovemos com a queda de um rei, choramos pelo homem, não pelo rei. A morte de um pai de família humilde poderia ser táo ou mais comovente que a morte de um monarca. Porém, os pleitos 
românticos não seriam facilmente acatados. Hegel (1964, p. 396-398), por exemplo, salientava as dificuldades de se manter o drama no patamar da arte abdicando da linguagem versificada, elevada, não julgava ser possível fazer teatro artístico em prosa. Contudo, ainda que não tenha sido fácil ao Romantismo encontrar soluções estéticas para representar os dramas desses heróis rebaixados, décadas depois o Realismo não apenas deu o tom ao drama social, mas ainda ensinou, por vias diversas, a tornar poético o palco das desgraças que acometem os homens comuns.

Não precisamos tecer consideraçóes sobre o sucesso do drama social, gênero que nasce burguês, mas que não tarda a acolher classes as mais profundamente carentes de poder econômico e social. A partir do século XIX, um amplo espectro de personagens representativos de classes socialmente excluídas assomaria aos palcos e encontraria as mais diversificadas formas, não apenas de nos comover, mas de afirmar a dignidade humana em luta contra o sofrimento. Esses dramas, que autores, como Williams (2002), consideram "tragédias modernas", lançam-se contra perspectivas acadêmicas como a de Steiner, que elitizam a própria crítica. Para além das contendas, o teatro conquistou o direito de representar nos palcos a dor dos excluídos e a dramaturgia do século XX foi pródiga em dizer o que havia para ser dito em termos de conflitos sociais. Contudo, a história do drama ainda não acabou...

Uma questão mais contemporânea que trago para discussão nas consideraçóes finais é a seguinte: um novo fenômeno parece estar posto nos dias atuais. Trata-se, para falarmos mais uma vez com Williams (2002), de uma nova "estrutura de sentimento" a enfronhar-se na arte. Tem ficado cada vez mais evidente que os poderosos precisam retornar aos palcos, não mais com a altivez dos antigos heróis, mas sob perspectivas afeitas às crises das sociedades submersas no capitalismo globalizado, que não prescindem da paródia como gênero que favorece a ironia, o sarcasmo. Cantamos as dores das vítimas, dos explorados. Talvez seja hora de saltar novas muralhas da vida social.

É por vias demolidoras que os poderosos têm reaparecido como protagonistas no teatro contemporâneo. E nada mais apropriado à representaçáo desse fenômeno do que fazê-los voltar como paródias dos antigos mitos. Tomarei aqui dois exemplos de peças que apresentam figuras poderosas do nosso próprio tempo em molduras degradantes. 
Em Ariel, peça da dramaturga irlandesa Carr (2009), inspirada na Oresteia de Ésquilo, um político ambicioso, Fermoy Fitzgerald, obcecado pelo desejo de se eleger, oferece a própria filha, Ariel, em sacrifício a um deus terrível. No lugar dos valores heroicos afirmados pelos gregos, uma absoluta distorção ética e uma estética devotada a fornecer o retrato da degradação atual do cenário político. A ambição, a crença de um político corrupto e mau em uma religião centrada em negociatas, a manipulação da mídia a favor dos poderosos, o cinismo, a hipocrisia reinante nas instituiçóes que dão suporte ao logro e ao embuste, enfim, um flagrante da contemporaneidade que todos conhecemos e que estamos testemunhando na atualidade como um subproduto do capital global. Em toda a peça, a reificação sem limites, objetivação de um mundo no qual a tragédia deixa de ser transgressão à ordem para ser pura desordem, numa perspectiva tão degradante que não há a quem recorrer para se fixar a verdade ou a justiça, sobrando-nos apenas, para o resgate de alguma dignidade possível ao humano, o retorno do corpo morto de Ariel, que assome das águas nas quais havia sido afogada como signo da recusa da natureza à podridão do mundo dito civilizado.

Em outra perspectiva, igualmente degradante para os poderosos, Kane (2002), na peça intitulada Phaedra's Love, retoma o antigo mito de Fedra: apenas agora a trama faz aportar ao teatro uma esfera palaciana que reflete a vida consumista da sociedade contemporânea. Ironicamente, o palácio faz-se referência mimética às famílias reais da atual Europa, em relação às quais os súditos, assim como milhóes de espectadores mundo afora, fazem-se de "público", ávidos por acompanhar, por via da mídia sensacionalista, as ações e as transgressóes de reis, rainhas, príncipes e princesas, que cada vez mais se despedem do imaginário dos contos de fadas. A família real enquadrada pelo drama de Sarah Kane apresenta-se como uma família desconectada, problemática e caricatural, como as famílias que povoam as telenovelas ou os reality shows contemporâneos, apenas com muito mais dinheiro e poder. Central aos conflitos da trama, o papel de Hippolytus merece destaque. Enquanto o Hipólito grego de Eurípedes, assim como o Hipólito latino de Sêneca, faziam-se heróis solitários, fugindo da urbes para se isolarem na floresta e ali cultuarem Ártemis, a deusa casta, esse Hippolytus inglês isolase não somente no espaço doméstico, mas também no interior de si mesmo. É assim que busca tragar o mundo para dentro do seu próprio ser perdido nas entranhas do eu... Devora ininterruptamente hambúrgueres, chips, do- 
ces, drogas, filmes de Hollywood... Em sua reclusão, até o sexo é consumido em experiência solo: masturba-se e engole o prazer a seco, lambuza-se, espirra e goza nas mesmas meias em que aspira chulé. Nada tem a doar, a dividir, apenas entrega-se ao desejo de consumir, de tragar o mundo em busca de um prazer que jamais se realiza, versão contemporânea - materialista e consumista - de uma apreciação filosófica de Schopenhauer acerca da natureza trágica pulsante na insatisfação dos humanos desejos: "jamais verdadeiro alvo, jamais satisfação final, em nenhuma parte um lugar de repouso" (SCHOPENHAUER, 2001, p. 324). Que essa maldição do consumismo, representada como ânsia de escapar ao vazio existencial, encaminhe o protagonista para uma grande tragédia aos moldes gregos é o que faz dessa paródia um exemplo de demolidora crítica política e social.

Esse retorno paródico aos mitos no teatro contemporâneo permite-nos pensar, com Hutcheon (2004), que a arte pós-moderna tem se manifestado, sim, como recusa e denúncia, não apenas como alienação. Do ponto de vista estético, esses novos dramas desestabilizam antigas convençóes, utilizando a paródia como instrumento de desconstrução de valores e de crítica a instituições. Se a ação trágica foi milenarmente definida como imitação da vida, se jamais foi possível dissociar as açóes humanas eticamente motivadas da problemática da legitimação social, não surpreende, então, que na crise de fundamentos confrontada na dramaturgia "pós-moderna", o teatro decida reconvocar os poderosos e, de forma zombeteira, como escracho, ou como pastiche, como prefere Jameson (1991, p. 17), subverter radicalmente o sentido de legitimação social, concedendo, emblematicamente, a figuras representativas das nossas elites os mais degradantes e indesejados papéis.

\section{REFERÊNCIAS}

ARISTÓTELES. Poética. Tradução de Eudoro de Sousa. Porto Alegre: Globo, 1966. AUERBACH, Erich. Mimesis: a representação da realidade na literatura ocidental. São Paulo: Perspectiva, 1994.

CARR, M. Ariel. In: MARINA CARR: Plays 1. Londres: Faber \& Faber, 2009.

ELIADE, M. Mito do eterno retorno. Tradução de José Antonio Ceschin. São Paulo: Mercuryo, 1992. 
FRYE, N. O código dos códigos. A Bíblia e a Literatura. Tradução e notas de Flávio Aguiar. São Paulo: Boitempo, 2004.

HEGEL. Estética: Poesia. Tradução de Álvaro Ribeiro. Lisboa: Guimarães Editores, 1964.

HORÁCIO. Arte Poética. In: ARISTÓTELES; HORÁCIO; LONGINO. A Poética Clássica. Tradução de Jaime Bruna. São Paulo: Cultrix, 1990.

HUTCHEON, L. A Poetics of Postmodernism: history, theory, fiction. Nova York: Routledge, 2004.

JAMESON, F. Postmodernism, or the Cultural Logic of Late Capitalism. Durham: Duke University Press, 1991.

KANE, S. Phaedra's Love. Londres: Bloomsbury Academic, 2002.

KELLY, H.A. Ideas and forms of tragedy from Aristotle to the Middle Ages. Cambridge: Cambridge University Press, 1993.

LESSING, G.E. Hamburg dramaturgy. Translated by Helen Zimmern. Introduction by Victor Lange. Nova York: Dover Publications, 1962.

SCHOPENHAUER, A. O mundo como vontade e representação. Tradução de M. F. Sá Correia. Rio de Janeiro: Contraponto, 2001.

SHAKESPEARE, William. Hamlet. In: The complete works. Nova York: Gramercy Books, 1975. p. 1071-1112.

SPERBER, S.F. Fiç̧ão e Razão: uma retomada das formas simples. São Paulo: Hucitec, 2009.

STEINER, G. A morte da tragédia. Tradução de Isa Kopelman. São Paulo: Perspectiva, 2006.

WILliAMS, R. Tragédia Moderna. Tradução de Betina Bischof. São Paulo: Cosac Naify, 2002.

Recebido em 02 de agosto de 2017. Aceito em 23 de março de 2018. 